
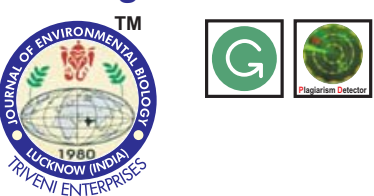

\title{
Effect of mangrove plant (Sesuvium portulacastrum) extract against Vibrio harveyi during shrimp larviculture
}

Authors Info

Masilamani Dineshkumar', Sudalayandi Kannappan ${ }^{1 *}$ and Krishnamoorthy Sivakumar,

${ }^{1}$ Nutrition, Genetics and Biotechnology Division, ICAR - Central Institute of Brackishwater Aquaculture, Chennai-600 028, India

${ }^{2}$ ICAR - Krishi Vigyan Kendra, Tamil Nadu Veterinary and Animal Sciences University, Kattupakkam - 603 203, India

*Corresponding Author Email : sudalikanna@gmail.com

Key words

Antagonism,

Sesuvium portulacastrum,

Shrimp larviculture

Vibrio harveyi

Publication Info

Paper received: 10.11 .2015

Revised received : 07.03.2016

Re-revised received : 25.06.2016

Accepted: 13.07.2016
Abstract

Aim : The present study aimed at finding a potential antagonistic activity of the leaves of mangrove plant Sesuvium portulacastrum against pathogenic Vibrio harveyiduring shrimp larviculture.

Methodology : Crude extract obtained from the leaves of mangrove plant $S$. portulacastrum was screened for its antagonistic activity against $V$. harveyi and the minimum inhibitory concentration was determined. Crude extract was characterized for its phytochemical composition by GC-MS and FTIR analysis. The antagonistic activity of $S$. portulacastrum crude extract was tested against $V$. harveyi during Penaeus monodon larviculture.

Results : MIC of S. portulacastrum extract was $100 \mu$ g against $1 \times 10^{8} \mathrm{CFUml}{ }^{-1}$ of $\mathrm{V}$. harveyi. When V. harveyi was cultured in Luria Bertani broth with crude extract of $S$. portulacastrum $\left(100 \mu \mathrm{g} \mathrm{ml}^{-1}\right)$ the growth and its virulence factors became weak. The cumulative percentage on mortality of postlarvae was $54 \%$ in 30 days, whereas control tank showed $67 \%$ mortality. Differences in reduction on the cumulative percentage mortality in the treatment tank was $13 \%$ as compared to control. Using statistical analysis, significant differences $(P<0.05)$ were observed between control and treatment.

Interpretation : This study endorse that crude extract of $S$. portulacastrum can be used as non-antibiotic and bio-therapeutic proxy to control bio-luminescence disease causing V. harveyi in the shrimp larviculture practice.

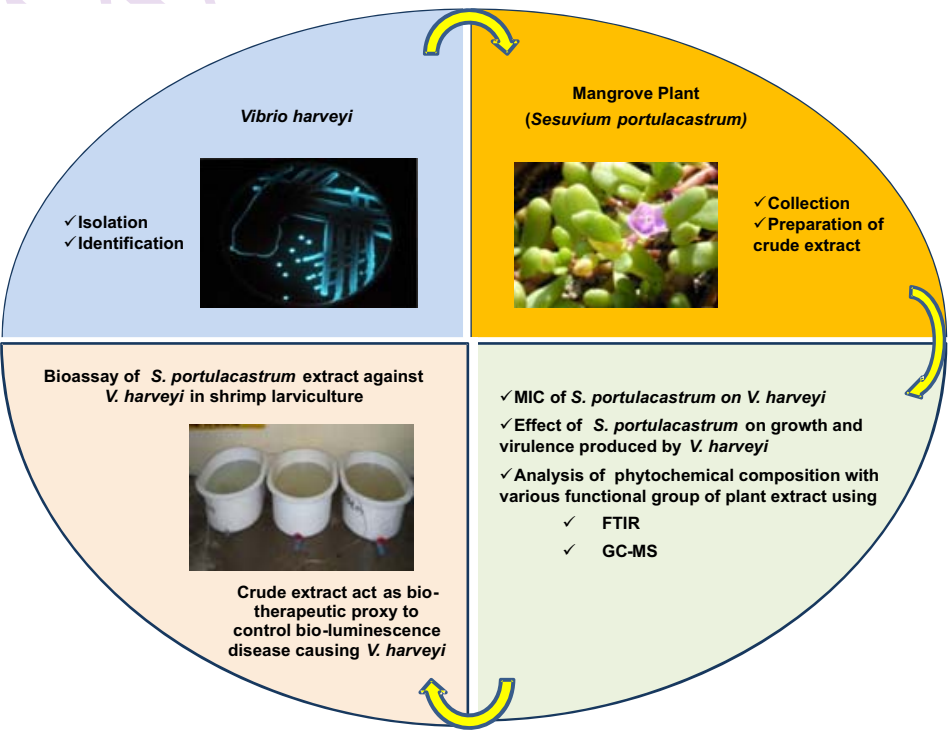




\section{Introduction}

Vibrio harveyi is one of the primary and virulent bacterial pathogen of Vibrionaceae family, which has been documented as causative agent for large-scale mortality in all the stages of Penaeid shrimp hatchery systems. Inappropriate application of chemicals or disinfectants for controlling Vibrio outbreaks could outcome in the progress of resistant among the bacteria (Vaseeharan et al., 2010). Dissimilar technologies have been familiarized to govern bio-luminescent bacteria in the shrimp grow-out and larviculture systems. "Green-water culture system" which is an innovative technique used in aquaculture, wherein the shrimps or fish are co-cultured with abundant microalgae such as Chlorella, but yet to be proved in farming trials. Probiotic bacteria have been used comprehensively for controlling various fish diseases, but high doses are indispensable and unable to maintain in many cases (Defoirdt et al., 2007). Therefore, the quest for alternate methods to control infection caused by antibiotic-resistant Vibrios are imperative challenge for sustainable development of aquaculture. Henceforth, in lieu of the chemical preservatives alternative bio-inhibitors extracted from marine plants may be used to control marine Vibrios.

Mangrove plants have primary and secondary metabolites such as proteins, carbohydrates, carotenoids, hydrocarbons, aliphatic alcohols, polyunsaturated fatty acids, lipids, pheromones, phorbol esters, phenolics, steroids, terpens, tannins and glycosides etc. (Bandaranayake, 2002). These metabolites were described for bioactive substances as bactericidal, fungicidal, pharmaceutical agents for animal and human beings (Suryati et al., 2002). Among the mangrove associated plants, Sesuvium portulacastrum is known as "Sea purslane" belongs to family Aizoaceae and grows in the Mediterranean coast and sub-tropical areas around the world. In traditional medicine, Sesuvium has been used for the treatment of conjunctivitis, leprosy, dermatitis and toothache (Chandrasekaran et al., 2011). S. portulacastrum has a long history of use in folk medicine in countries such as Zimbabwe and South Africa. Abirami and Rameswari (2013) had described antiVibrio cholera activity against the chloroform and petroleum ether extracts obtained from S. portulacastrum. Oil was extracted from the fresh leaves of $S$. portulacastrum and used as antagonistic agent against bacteria and fungi (Michael et al., 2006). Therefore, the present study divulges that the antagonism of crude ethyl acetate extracts of $S$. portulacastrum against growth, virulence factors of $V$. harveyi and its effect on $V$. harveyi during larviculture of Penaeus monodon.

\section{Materials and Methods}

Isolation of microorganism : $V$. harveyi was isolated from the water samples collected from Muttukadu Experimental Station (MES) of ICAR-CIBA at Chennai. Isolates were identified by various bio-chemical tests such as arginine dihydrolase (-), lysine
$(+)$, ornithine decarboxylase $(+)$, gelatinase $(+)$, Vogesproskauer $(-)$, D-glucosamine (-), etc (Abraham and Palaniappan, 2004) and compared with standard type strain V. harveyi ATCC 25919. The isolates were re-confirmed by streaking in $V$. harveyi Selective agar (VHSA) and stored in VHSA slants at $4^{\circ} \mathrm{C}$ (Harris et al., 1996).

Collection of S. portulacastrum and preparation of extract : Sesuvium portulacastrum was collected from MES of ICARCIBA, Tamil Nadu, India. The leaves were shade dried at room temperature then pulverized by a mechanical grinder and stored in an airtight container. Fourty $g$ of $S$. portulacastrum powder was extracted with $200 \mathrm{ml}$ of ethyl acetate (boiling point $76-78^{\circ} \mathrm{C}$ ) by Soxhlet apparatus.

Antagonism of $S$. portulacastrum leaf extract against $V$. harveyi by Well diffusion method : The crude extracts obtained from leaf of $S$. portulacastrum were subjected to antimicrobial assay through "Agar well diffusion assay". One hundred $\mathrm{ml}$ of Luria Bertani (LB) agar medium was prepared, inoculated with $100 \mu \mathrm{l}$ of $V$. harveyi (1.8 OD), mixed thoroughly and poured into Petri-dishes in replicates. Appropriate number of circular wells each $6 \mathrm{~mm}$ was cut in the solidified agar medium. A drop of soft agar $(0.85 \%)$ was used to seal the well. The wells were filled with extracts of various concentrations after dissolving in 30\% Dimethylsulfoxide (DMSO). The inoculated plates were incubated at $28^{\circ} \mathrm{C}$ for $24 \mathrm{~h}$. Zone of inhibitions were measured and tabulated (Ravikumar et al., 2011).

Fourier transform infra-red spectroscopy (FTIR) analysis : The shade dried S. portulacastrum leaves were ground as a fine powder with a pestle and mortar. The FTIR spectra were recorded using BRUKER IFS 66 model FTIR spectrometer in the region $4000-400 \mathrm{~cm}^{-1}$ by employing standard $\mathrm{KBr}$ pellet technique (D'Souza et al., 2008).

Gas chromatography and mass spectrometry analysis (GCMS) : Gas chromatography-mass Spectrometry (GC-MS) analysis for Ethyl acetate extract of $S$. portulacastrum was performed by using Agilent GC-MS-5975C with the Triple-Axis Detector equipped with an auto sampler. Peak identification of crude extract was performed by comparing with retention times of standards and the mass spectrum obtained was compared with those available in the NIST libraries (NIST 11- Mass Spectral Library 2011 version) with an acceptance criterion of a match above critical factor $80 \%$ (Musharraf et al., 2012).

Effect of S. portulacastrum extracts against the growth and virulence's produced by V. harveyi : LB broth of each $100 \mathrm{ml}$ was inoculated with $1.0 \mathrm{ml}$ of $V$. harveyi (1.8 OD) separately for control (without crude extract of Sesuvium leaves) and treatment (with crude extract of Sesuvium). One $100 \mu \mathrm{g}$ of extract per $\mathrm{ml}$ of LB broth was added and shaker incubated at $28^{\circ} \mathrm{C} / 100 \mathrm{rpm}$ for 5 days. Growth and luminescence produced by $V$. harveyi, both in 
the treatment as well as control was monitored for 5 days (Kannappan et al., 2013) using spectrophotometer (OD at 600 $\mathrm{nm}$ ) and Luminometer (Victor TM-X3, Perkin Elmer, USA).

Determination of virulence factors produced by $V$. harveyi : Two $\mathrm{ml}$ of $\mathrm{S}$. portulacastrum extract was added in LB broth was taken every day from control and treatment. Various virulence factors such as phospholipase activity, crude extracellular protein (bacteriocin), protease and luciferase produced by $V$. harveyi were determined. Cells harvested from the broth were spotinoculated onto nutrient agar separately with $5 \%$ egg yolk for phospholipase test (Manilal et al., 2010). The plates were then incubated at $37^{\circ} \mathrm{C} / 24 \mathrm{~h}$. The enzymatic activity of the bacteria (control and treated) was detected by observing the presence of clear zones around the spot.

\section{Antagonism of S. portulacastrum against V. harveyi}

Determination of protease using azocasein : The supernatant of $S$. portulacastrum leaves extract added in LB broth was used as crude protease enzyme and analyzed for protease activity (Olajuyigbe and Ajele, 2005). Protease enzyme activity was assessed using $500 \mu \mathrm{l}$ of $0.5 \%$ azocasein (w/v) (Sigma, USA) in Tris $\mathrm{HCl}$ buffer with $100 \mu \mathrm{l}$ enzyme solution and incubated for 60 $\min$ at $37^{\circ} \mathrm{C}$. The reaction was stopped by adding $500 \mu \mathrm{l}$ of $15 \%$ Trichloro acetic acid, incubated at $30^{\circ} \mathrm{C} / 15 \mathrm{~min}$ and then centrifuged at $4^{\circ} \mathrm{C} / 15 \mathrm{~min}$ at $3000 \mathrm{rpm}$. One $\mathrm{ml}$ of supernatant was added with $1.0 \mathrm{ml}$ of $\mathrm{NaOH}$ and absorbance was measured at $440 \mathrm{~nm}$ (One unit of protease activity is defined to be the amount of enzyme required to produce an absorbance change of 1.0 in a $1.0 \mathrm{~cm}$ cuvette under the condition of the assay). For estimating crude extracellular protein (bacteriocin), the cell suspension from $S$. portulacastrum extract added in LB broth from control and treatment were centrifuged at $5000 \times \mathrm{g}$ for 10 $\mathrm{min}$. The cells were separated out and supernatant was used for estimating the crude extracellular protein (Lowry et al., 1951).

Salt aggregation test : Adherence of $V$. harveyi was determined by Salt aggregation test. The cells obtained from the broth (treated and control) were washed with sterile $2.5 \% \mathrm{NaCl}$. The cells were suspended in sodium phosphate buffer ( $\mathrm{pH} \mathrm{6.8)}$ and OD was adjusted to 1.0 at $420 \mathrm{~nm}$. Fifty micro litre of cell suspension was mixed with equal volume of various molarities of ammonium sulphate ranged from 0.05 to $4.0 \mathrm{M}$ (molarity) in 96 well plates, kept at room temperature and observed for agglutination. The SAT values were recorded as lowest molarity of ammonium sulfate giving visible bacterial aggregation while evaluating bacterial cell surface hydrophobicity. Strains with SAT values $>4.0 \mathrm{M}, 2.0-4.0 \mathrm{M}, 1.0-2.0 \mathrm{M}$ and $0.0-1.0 \mathrm{M}$ were designated as no, low, moderate and high hydrophobicity, respectively (Qiao et al., 2012).

Bioassay of S. portulacastrum leaf extract against V. harveyi during shrimp larviculture : Plastic tanks ( 30 litre) were washed with $1 \% \mathrm{KMnO}_{4}$ solution and filled with 10 litre of $18 \pm 1$ PSU low saline water. Disease free postlarvae (PL 15 days) of Penaeus monodon, procured from private shrimp hatchery were acclimatized in $18 \mathrm{PSU}$ for 3 days before starting the experiment at $28 \pm 1^{\circ} \mathrm{C}$ with continuous aeration. The postlarvae (PL) had an average body weight of $18-19 \mathrm{mg}$ and 450 numbers of PL were stocked in each experimental tanks. Control tank was inoculated with $10 \mathrm{ml} \mathrm{V}$. harveyi (1.8 OD) alone and the treatment tank was inoculated with $10 \mathrm{ml}$ V. harveyi (1.8OD) with crude extract of $S$. portulacastrum $\left(100 \mathrm{\mu g} \mathrm{ml}^{-1}\right)$. The experiment was conducted for 30 days without exchanging water and PL feed given twice a day. The tanks were covered to evade air-borne contamination and the effect of $S$. portulacastrum leaf extract was tested against $V$. harveyi during shrimp larviculture. Dead PL were collected and cumulative percentage mortality was ascertained from the tanks. Water quality parameters like salinity, temperature, and $\mathrm{pH}$ were measured using salinometer, thermometer and $\mathrm{pH}$ meter respectively (Kannappan et al., 2012). Enumerations of total heterotrophic bacteria (THB) and V. harveyi counts (Harris et al., 1996) were determined both in the treatment and control tanks using Trypticase soya agar (TSA) and $V$. harveyi selective agar medium (VHA) for 5 days. All the experimental values were average of three replications, expressed with standard deviation.

Statistical analysis : The replicated data obtained from the $S$. portulacastrum extract against growth and virulence factors of $V$. harveyi with cumulative percentage of mortality (CPM) during $P$. monodon larviculture were expressed with mean value \pm standard deviation. CPM was calculated by Cumulative frequency / total number of observations $(n) \times 100$. Analysis of variance following the statistical programme for the social sciences (SPSS, ver. 16.0) was used to assess the significance $(P<0.05)$ between control and treatment.

\section{Results and Discussion}

The minimum inhibitory concentration (MIC) of $S$. portulacastrum extract was $100 \mu \mathrm{l}\left(1 \mathrm{mg} \mathrm{ml}^{-1}\right)$ against $100 \mu \mathrm{l}$ of $1 \times 10^{8} \mathrm{CFU} \mathrm{ml}{ }^{-1}$ of $\mathrm{V}$. harveyi as determined by "Agar well diffusion assay". But S. portulacastrum extract showed MIC and MBC of 50 $\mu \mathrm{g} \mathrm{ml}^{-1}$ against Staphylococcus aureus and E. coli (Al-Azzawi et al., 2012). Crude S. portulacastrum extract showed a maximum zone of inhibition, $13.9 \mathrm{~mm}$ (excluding the well) against $V$. harveyi at $200 \mathrm{\mu g} \mathrm{ml}^{-1}$ concentration, whereas no inhibition was observed when DMSO (30\%) was used as positive control against $V$.

Table 1 : Antagonism of crude leaf extract of $S$. portulacastrum against $V$. harveyi

\begin{tabular}{lll}
\hline Antagonism & \multicolumn{1}{l}{ Concentration $(\boldsymbol{\mu g})$} & Zone of inhibition $(\mathrm{mm})$ \\
\hline Crude extract & 100 & $9.4 \pm 0.2$ \\
Crude extract & 150 & $11.3 \pm 0.4$ \\
Crude extract & 200 & $13.9 \pm 0.6$ \\
Control (30\% DMSO) & $50(\mu \mathrm{l})$ & $\mathrm{ND}$ \\
\hline
\end{tabular}

Values are mean \pm S.D. for three observations, $N D=$ Not detected 
Table 2: GC-MS analysis of various compounds present in the leaf extract of $S$. portulacastrum

\begin{tabular}{|c|c|c|c|c|c|}
\hline $\begin{array}{l}\text { Peak } \\
\text { No. }\end{array}$ & $\begin{array}{l}\text { Retention } \\
\text { time (min) }\end{array}$ & Compound name & $\begin{array}{l}\text { Peak area } \\
(\%)\end{array}$ & $\begin{array}{l}\text { Molecular } \\
\text { formula }\end{array}$ & $\begin{array}{l}\text { Molecular } \\
\text { weight }\end{array}$ \\
\hline 1 & 9.375 & Pyrazine carboxamide, 3,4-dihydro-3-oxo- & 2.28 & $\mathrm{C}_{5} \mathrm{H}_{5} \mathrm{~N}_{3} \mathrm{O}_{2}$ & 139.112 \\
\hline 2 & 12.585 & Decane, 2-methyl- & 2.28 & $\mathrm{C}_{11} \mathrm{H}_{24}$ & 156.308 \\
\hline 3 & 13.456 & $2(3 \mathrm{H})$-Benzoxazolone & 50.09 & $\mathrm{C}_{7} \mathrm{H}_{5} \mathrm{NO}_{2}$ & 135.12 \\
\hline 4 & 13.573 & $2(4 \mathrm{H})$ - Benzofuranone, 5,6,7,7a-tetra hydro - 4,4,7a-trimethyl- & 7.51 & $\mathrm{C}_{11} \mathrm{H}_{16} \mathrm{O}_{2}$ & 180.243 \\
\hline 5 & 14.313 & Tetradecane & 1.76 & $\mathrm{C}_{14} \mathrm{H}_{30}$ & 198.388 \\
\hline 6 & 15.461 & Eicosane, 10 - methyl- & 3.01 & $\mathrm{C}_{21} \mathrm{H}_{44}$ & 296.574 \\
\hline 7 & 16.55 & Hentriacontane & 1.12 & $\mathrm{C}_{31} \mathrm{H}_{64}$ & 436.839 \\
\hline 8 & 16.942 & Bicyclo [4.1.0] heptane, 2-methyl- & 6.08 & $\mathrm{C}_{8} \mathrm{H}_{14}$ & 110.109 \\
\hline 9 & 17.000 & 2-Pentadecanone, 6,10,14-trimethyl & 6.75 & $\mathrm{C}_{18} \mathrm{H}_{36} \mathrm{O}$ & 268.477 \\
\hline 10 & 17.378 & 3,7,11,15-Tetramethyl-2-hexadecen-1-ol & 2.43 & $\mathrm{C}_{20} \mathrm{H}_{40} \mathrm{O}$ & 296.531 \\
\hline 11 & 18.162 & n-Hexadecanoic acid & 7.18 & $\mathrm{C}_{16} \mathrm{H}_{32} \mathrm{O}_{2}$ & 256.424 \\
\hline 12 & 18.598 & Ethylamine, 2-(adamantan-1-yl)-1-methyl- & 1.74 & $\mathrm{C}_{13} \mathrm{H}_{23} \mathrm{~N}$ & 193.183 \\
\hline 13 & 19.542 & 3,3-Dimethyl-4-methylamino-butan-2-one & 1.89 & $\mathrm{C}_{7} \mathrm{H}_{15} \mathrm{NO}$ & 129.115 \\
\hline 14 & 19.861 & 4,6-dimethyl-2-propyl-1,3,5-dithiazinane & 3.65 & $\mathrm{C}_{8} \mathrm{H}_{17} \mathrm{NS}_{2}$ & 191.08 \\
\hline 15 & 19.905 & L-Alanine-4-nitroanilide & 2.24 & $\mathrm{C}_{9} \mathrm{H}_{11} \mathrm{~N}_{3} \mathrm{O}_{3}$ & 209.201 \\
\hline
\end{tabular}

Table 3: Various functional groups of compounds detected in leaf extract of S. portulacastrum by FTIR

\begin{tabular}{lll}
\hline Frequency $\left(\mathrm{cm}^{-1}\right)$ & Bond & Functional group \\
\hline 2921.8 & C-H stretch, O-H stretch & Alkanes, carboxylic acids \\
1639.1 & C-C stretch (in-ring) & Aromatics \\
1446.2 & C-O stretch, C-N stretch & alcohols, carboxylic acids, \\
1046.2 & C-Cl stretch, C-Br stretch & esters, ethers \\
596.2 & & aliphatic amines, alkyl halides \\
\hline
\end{tabular}

Table 4: Effect of crude S. portulacastrum leaf extract against growth and virulence factors of $V$. harveyi

\begin{tabular}{|c|c|c|c|c|c|c|c|c|c|c|c|c|}
\hline \multirow[t]{2}{*}{ Day } & \multicolumn{2}{|c|}{$\begin{array}{l}\text { Growth of } V \text {. harveyi } \\
\quad(600 \mathrm{~nm})\end{array}$} & \multicolumn{2}{|c|}{$\begin{array}{l}\text { Luciferase } \\
\text { activity (CPS) }\end{array}$} & \multicolumn{2}{|c|}{$\begin{array}{l}\text { Phospholipase } \\
\text { activity }\end{array}$} & \multicolumn{2}{|c|}{$\begin{array}{l}\text { Salt aggregation } \\
\text { test (M - Molarity) }\end{array}$} & \multicolumn{2}{|c|}{ Bacteriocin $(660 \mathrm{~nm})$} & \multicolumn{2}{|c|}{ Protease $(440 \mathrm{~nm})$} \\
\hline & Treated & Control & Treated & Control & Treat & Control & Treated & Control & Treatment & Control & Treatment & Control \\
\hline & & & 170 & 254 & $\mathrm{NL}$ & & & & & & & \\
\hline & 0 & 3 & 15 & 21 & ND & ++ & 1.2 & 0 & 1 & 1. & .07 & 0.08 \\
\hline & \pm 0.02 & 2 & 10 & 224 & + & ++++ & 2.00 & 0 & 02 & .20 & .09 & $0.38 \pm 0.06$ \\
\hline & sou & \pm 0.01 & 11 & 13 & + & ++++ & 1.75 & 1. & 02 & $1.53 \pm 0.10$ & $8 \pm 0.01$ & $0.44 \pm 0.03$ \\
\hline- & $0.28 \pm 0.01$ & $1.11 \pm 0.01$ & 143 & 198 & ++ & +t++ & 2.75 & 0.75 & $0.83 \pm 0.01$ & $2.04 \pm 0.11$ & $0.081 \pm 0.06$ & $0.48 \pm 0.09$ \\
\hline
\end{tabular}

Control : V. harveyi untreated with crude extract and treated: treatment of crude extract of $S$. portulacastrum; Here : + = low or weak, $++=$ moderate, +++ $=$ high,$++++=$ very high, $\mathrm{ND}=$ not detected

harveyi. Paulpriya et al. (2013) reported that S. portulacastrum extract had phenolic and flavanoid compounds, which were responsible for bacterial inhibition. Various concentrations of $S$. portulacastrum extract showed antagonism against $V$. harveyi (Table 1).

Chandrasekaran et al. (2011) described antimicrobial activity of $S$. portulacastrum extract against human pathogenic bacteria. The essential oil extracted from $S$. portulacastrum exhibited antagonism against Acetobacter calcoacetica, B.subtillis, Clostridium sporogenes, C. perfringens, E.coli, Salmonella typhii, Staphylococcus aureus and Yersinia enterocolitica (Magwa et al., 2006). The antimicrobial activity of leaf extract obtained from $S$. portulacastrum shown antagonism against $S$. aureus, E. coli, Klebsiella pneumonia, V. cholerae and Pseudomonas aeruginosa (Abirami and Rameshwari, 2013). Chandrasekaran et al. (2011) reported higher amount of saturated and unsaturated fatty acids from $S$. portulacastrum, which might be responsible for antagonism. The GC-MS profile of ethyl acetate extract obtained from $S$. portulacastrum leaf shown several compounds such as $2(3 \mathrm{H})$ Benzoxazolone (50.09\%),2(4H)-Benzofuranone, 5,6,7,7atetra-hydro-4,4,7a-trimethyl (7.51\%) and $\mathrm{n}$-Hexadecanoic acid $(7.18 \%)$ (Table 2$)$. 


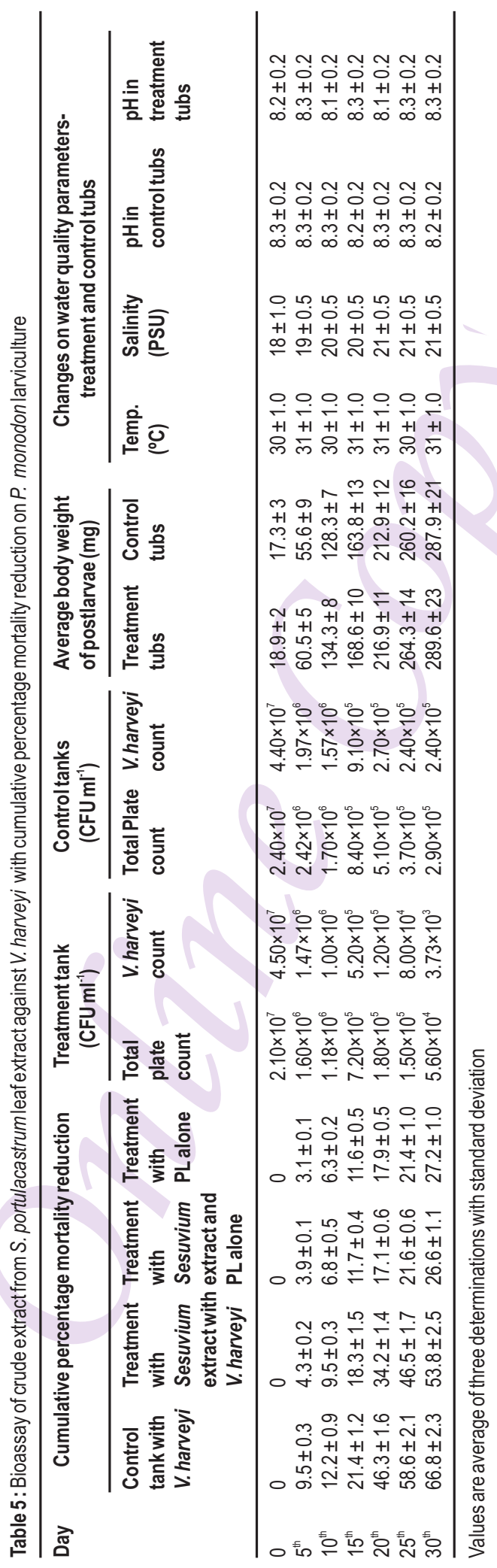


FTIR analysis, (Table 3) of the crude extract of $S$. portulacastrum showed various functional compounds such as alkanes, aromatics, alcohols, carboxylic acids, esters, ethers, aliphatic amines, alkyl halides, etc. Sheela and Udayakumari (2013) reported about 1-Monolinoleoyl-glycerol trimethylsilylesther (19.29\%) and Vitamin E (44.79\%) in the leaf extract and Benzoic acid, 4-ethoxy-ethyl ester (23.03\%), Oleic acid (15.99\%) as chief phyto-constituents in the stem of $S$. portulacastrum. However, S. portulacastrum extract prepared from the leaves were reported to have $2(3 \mathrm{H})$-Benzoxazolone at high level (50.09\%) followed by Benzofuranone $(7.51 \%$ ) and Hexadecanoic acid respectively. In the present study, the extracts of $S$. portulacastrum using different solvents, showed various phytochemical compounds based on their solubility. The antagonistic effect of $S$. portulacastrum might be due to presence of phytochemicals in the extract.

The extract of $S$. portulacastrum was suppressed the growth of $V$. harveyi from $0.41 \mathrm{OD}$ to $0.28 \mathrm{OD}$ for first 5 days in treatment whereas growth increased from 0.47 to $1.11 \mathrm{OD}$ in control. Similarly, virulence activities such as luciferase, bioluminescence (Table 4), phospholipase became weak. But in control these activities were strong. Correspondingly, in treatment crude bacteriocin was reduced from 1.36 to $0.83 \mathrm{OD}$ as compared to control (1.79 to $2.04 \mathrm{OD})$ and the level of protease production also decreased from 0.22 to $0.08 \mathrm{OD}$. These values were statistically interpreted and significant differences $(P<0.05)$ between the leaf extract of $S$. portulacastrum treated against $V$. harveyiand control.

Hydrophobic microbes are capable of adhering to the oil/ water interface and utilizing oil components as a source of energy for growth and metabolism. This hydrophobic nature would also help the bacteria to adhere on the external surfaces and tissues of a host which is in initial step in the infection of a host and subsequent occurrence of disease. It was broadly accepted that hydrophobic and biofilm productions were the major factors in the adhesive process and survival of pathogens in cells (Zoueki et al., 2010). But, S. portulacastrum extract treated V. harveyi, cells showed SAT values in between 1.00 - 2.75 M (Table 4) which was indicates hydrophobic nature of bacteria. Qiao et al. (2012) also reported that, $V$. harveyi cells were more hydrophobic in nature. Under larviculture experiment, the cumulative percentage of mortality value increased in control due to $\mathrm{V}$. harveyi (Sivakumar et al., 2014) from 9 to $67 \%$ in $5^{\text {th }}$ to $30^{\text {th }}$ days. But in treatment, the CPM was reduced from 4 to $54 \%$ till $30^{\text {th }}$ day. The difference among the CPM in the treatment tank was $13 \%$ as compared to control (Table 5). The essential oil of $S$. portulacastrum exhibited antibacterial activity against Acetobacter calcoacetica, $B$. subtillis, C. porogenes, C. perfringens, E.coli, S. typhii, S.aureus and Yersinia enterocolitica (Michael et al., 2006). Crude aqueous extract of S. portulacastrum, even show significant enhancement on growth and metabolism in Labeo rohita fish (Johnson and Banerji, 2007).
The water quality parameters were observed as quiet normal and much dissimilarity was not observed due to treatment. The average initial load of $\mathrm{V}$. harveyi was $4.45 \times 10^{7} \mathrm{CFU} \mathrm{ml}{ }^{-1}$ during the first day of treatment and control tanks. The growth was then

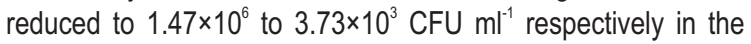
treatment tank as compared to control tank $1.97 \times 10^{6}$ to $2.40 \times 10^{5} \mathrm{CFU} \mathrm{ml} \mathrm{I}^{-1}$. The inhibitory activity may be due to the antioxidant, phenolic and flavonoids compounds present in the bark and leaf extracts of S. portulacastrum (Singh et al., 2013). It has been proved that mangrove plant extract controls the infection caused by $V$. alginolyticus in Clown fish (Dhayanithi et al., 2012). Recent study showed that the essential oil extracted from the leaves of Sesuvium showed significant antifungal and antioxidant activity (Magawa et al., 2006).

The results of the present study revealed that the concentration of $100 \mathrm{~g} \mathrm{ml}^{-1}$ of $S$. portulacastrum extract was able to antagonize $10^{7}$ to $10^{3} \mathrm{CFU} \mathrm{ml^{-1 }}$ of $V$. harveyi in the treatment tank. Also the THB count of treatment tank decreased from $2.10 \times 10^{7} \mathrm{CFU} \mathrm{ml}{ }^{-1}$ to $5.60 \times 10^{4} \mathrm{CFU} \mathrm{m}^{-1}$ during the entire experiment period. The values observed from the bioassay of $S$. portulacastrum extract against $V$. harveyi during the $P$. monodon larviculture, proved significant differences $(P<0.05)$ between the S. portulacastrum extract treated with $V$. harveyi and control.

It can be concluded that the crude extract of $S$. portulacastrum was reduced even the mortality on $P$. monodon during larviculture caused by V. harveyi. The cost of production of crude $S$. portulacastrum extract was compared with molecular grade chemicals in the animal experiments. The decreased amount of cost was worked out up to $20 \%$.

\section{Acknowledgment}

The authors acknowledge the DBT, New Delhi, India for supporting this work under the sponsored project "Development of inhibitors for controlling quorum sensing luminescence causing V. harveyi in shrimp larviculture system" (Grant No: BT/PR/13383/AAQ/03/501/2009).

\section{References}

Abirami, H. and R. Rameshwari: Antibacterial and antifungal screening of Sesuvium portulacastrum extracts against leather contaminating organism. Int. J. Curr. Res., 5, 1376-1377 (2013).

Abraham, T.J. and R. Palaniappan: Distribution of luminous bacteria in semi-intensive Penaeid shrimp hatcheries of Tamilnadu, India. Aquaculture, 232, 81-90 (2004).

Al-Azzawi, A., A. Alguboori, M.Y. Hachim, M. Najat, A. Al Shaimaa and M. Sad: Preliminary phytochemical and antibacterial screening of Sesuvium portulacastrum in the United Arab Emirates. Pharmacognosy. Res., 4, 219-224 (2012).

Bandaranayake, W.M.: Bioactivities, bioactive compounds and chemical constituents of mangrove plants. Wetlands Ecol. Manag., 10, 421452 (2002).

Chandrasekaran, M., A. Senthilkumar and V. Venkatesalu: Antibacterial 
and antifungal efficacy of fatty acid methyl esters from the leaves of Sesuvium portulacastrum. Eur. Rev. Med. Pharmacol. Sci.,15, 775-780 (2011)

D'Souza, L., P. Devi, D.M. Shridhar and C.G. Naik: Use of Fourier Transforms Infrared (FTIR) spectroscopy to study cadmiuminduced changes in Padina tetrastromatica (Hauck). Anal. Chem. Insights, 3, 135-143 (2008).

Defoirdt, T., N. Boon, P. Sorgeloos, W. Verstraete and P. Bossier: Alternatives to antibiotics to control bacterial infections: Luminescent Vibriosis in aquaculture as an example. Trends Biotechnol., 25, 472-479 (2007).

Dhayanithi, N.B., T.T. Ajith Kumar and T. Balasubramanian: In vitro and experimental screening of mangrove herbal extract against $V$. alginolyticus in marine ornamental fish. World Acad. Sci., Engg. Technol., 6, 1310-1314 (2012).

Harris, L., L. Owens and S.A. Smith: Selective and differential medium for V. harveyi. Appl. Environ. Microbiol., 62, 3548-3550 (1996).

Kannappan, S., A. Kumar, Uzolhemere, F. Vanessa, N. Narayanan, G. Elisa and S. Richard: Detection of quorum sensing molecules from $V$. harveyi and use of synthetic furanone to control $V$. harveyi during shrimp larviculture. Afr. J. Biotechnol., 11, 14498-14508 (2012).

Kannappan, S., K. Sivakumar, P.K. Patil and R.N. Richard Kennedy: Extraction and detection of quorum sensing $\mathrm{N}$-acyl homoserine lactones from shrimp pathogen $V$. harveyi and antagonistic effect of terrestrial plants against its growth. Afr. J. Microbiol. Res., 726, 3275-3284 (2013).

Johnson, C. and A. Banerji: Influence of extract isolated from the plant Sesuvium portulacastrum on growth and metabolism in freshwater teleost, Labeo rohita. Fish Technol., 44, 229-234 (2007).

Lowry, O.H., N.J. Rosebrogh, A. Farr and R.J. Randal: Protein measurement with folin phenol reagent. J. Biol. Chem., 193, 265-275(1951).

Magwa, M.L., M. Gundidz, N. Gweru and G. Humphrey: Chemical composition and biological activities of essential oil from the leaves of Sesuvium portulacastrum. J. Ethnopharmacol., 103, 85-89 (2006).

Manilal, A., S. Sujith, J. Selvin, C. Shakir, R. Gandhimathi and G. Seghal Kiran: Virulence of Vibrios isolated from diseased black tiger shrimp Penaeus monodon, Fabricius. J. World Aquacul. Soc., 413, 332-343 (2010).

Michael, L.M., G. Mazaru, G. Nyasha and H. Godfred: Chemical composition and biological activities of essential oil from the leaves of Sesuvium portulacastrum. J. Ethnopharmacol., 103, 85-89 (2006).

Musharraf, S.G. and M.A. Ahmed: Biodiesel production from micro-algal isolates of southern Pakistan and quantification of FAME's by GCMS/MS analysis. J. Chem. Cent., 61, 149 (2012).

Olajuyigbe, F.M. and J.O. Ajele: Production dynamics of extracellular protease from Bacillus species. Afr. J. Biotechnol., 4, 776-779 (2005).

Paulpriya, K., M. Packia Lincy and V.R. Mohan: Total phenolic, flavonoid contents and in vitro antioxidant activity of leaf of Sesuvium portulacastrum L (Aizoaceae). J. Adv. Pharm. Edu. Res., 3, 67-75 (2013).

Qiao, G., H. Li, D.H. Xu and S. Park: Modified a colony forming unit microbial adherence to hydrocarbons assay and evaluated cell surface hydrophobicity and biofilm production of Vibrio scophthalmi. J. Bacteriol. Parasitol., 3, 130 (2012).

Ravikumar, S., G.N. Anitha Anandha, G. Palani Selvan and Kalaiarasi: A in vitro antibacterial activity of coastal medicinal plants against isolated bacterial fish pathogens. Int. J. Pharma. Res. Dev., 3, 109 -116 (2011).

Sheela, D. and F. Uthayakumari: GC-MS analysis of bioactive constituents from coastal sand Dune taxon-Sesuvium portulacastrum (L). Biosci. Disc., 4, 47-53 (2013).

Singh, C., R.N.S. Boopathy, K. Kathiresan, S. Anandhan, S.K. Sahu and A. Kumar: Effect of bioactive substances from mangroves on antioxidant, antibacterial activity and molecular docking study against lung and oral cancer. J. Free Rad. Antioxid, Photon, 139, 226-236 (2013).

Sivakumar, K., S. Kannappan, M. Dineshkumar and P. K. Patil: Antagonism of marine macro alga, Kappaphycus alvarezii extract against luminescence disease causing $V$. harveyi during Penaeus monodon larviculture. Afri. J. Microbiol. Res., 8,458-469 (2014).

Suryati, E. and Y. Hala: Bioactive substances of mangrove Excoecaria agallocha as shrimp diseases inhibitor. Marin. Chim. Acta., 2, 9-14 (2002).

Vaseeharan, B., P. Ramasamy and J.C. Chen: Antibacterial activity of silver nanoparticles (AgNps) synthesized by tea leaf extracts against pathogenic $V$. harveyiand its protective efficacy on juvenile Feneropenaeus indicus. Lett. Appl. Microbiol., 50, 352-356 (2010).

Zoueki, C.W., N. Tufenkji and S. Ghoshal: A modified microbial adhesion to hydrocarbons assay to account for the presence of hydrocarbon droplets. J. Colloid. Interf. Sci., 344, 492-496 (2010). 